\title{
Is the death rate from asthma exaggerated? Evidence from West Cumbria
}

\author{
W T Berrill
}

\begin{abstract}
Although the death rate from asthma in England and Wales is reported to be about 2000 a year, clinical experience suggests that it is much rarer. Doctors in West Cumbria health district could recall only seven cases in 14 years. Examination of case notes of patients officially recorded as dying of asthma showed that many were aged over 60 and cigarette smokers. An alternative cause of death was evident in over half the patients. If the picture is representative of that in the whole of Britain the reported mortality from asthma may be much too high.
\end{abstract}

The rate of death from asthma seems to be increasing despite advances in treatment. ${ }^{1.5}$ The number of deaths from asthma in England and Wales is widely reported to be about 2000 a year. This figure is derived from national mortality statistics taken from death certificates and equates to about four asthma deaths per 100000 population per year. In a comparatively small health district such as West Cumbria (137000 population) five to six deaths from asthma would be expected each year.

In the 14 years since 1978, during which I have been the only consultant physician in respiratory medicine in West Cumbria, there should, according to the above statistics, have been at least 70 deaths from asthma and yet I know of very few, having personal knowledge of only three. I questioned physician colleagues, local paediatricians, long serving nursing staff on medical wards and in the accident and emergency department, pathologists, and the coroner and found two further possible cases. I also approached all general practitioners in West Cumbria. Most of them knew of no patient who had died of asthma during the past five or more years, but three possible cases were referred to, one of which was already accounted for. In addition, 20 of the worst asthmatic patients in the district, who had been identified mainly between 1978 and 1982 and had been offered the option of self admission, were all alive in 1992.

\section{Asthma statistics}

I decided to look at the local statistics for asthma deaths in West Cumbria from the public health department for the years 1980 to 1989 . These showed an average annual mortality of four deaths per year for the 10 years as a whole. This was considerably more than the anecdotal evidence and clinical experience had suggested (less than one death per year), although slightly lower than the national figure. Asthma is usually thought of as a disease of young people, yet most of the patients had been aged over 55 at the time of

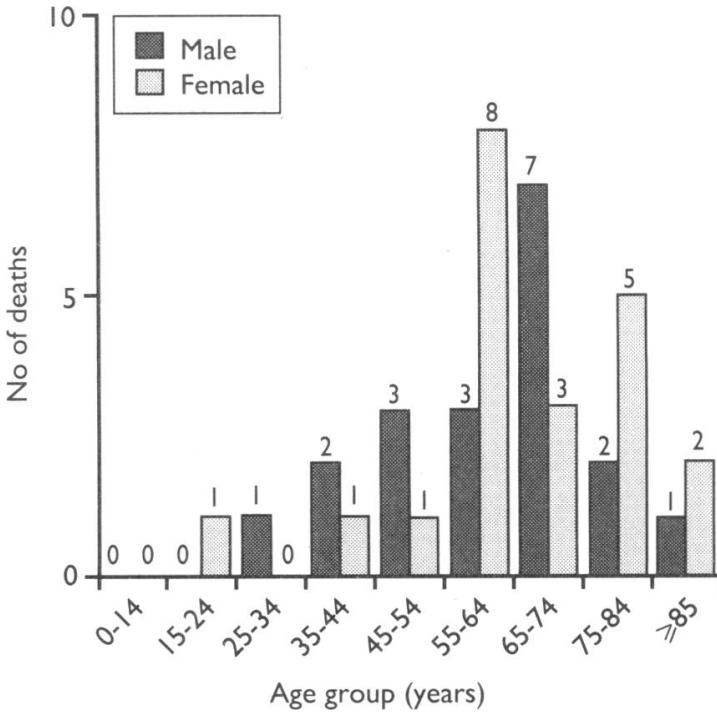

Number of deaths from asthma in West Cumbria District Health Authority 1980-9

death, a significant number being elderly (figure). The statistics for the whole of England and Wales also showed a preponderance of deaths in older age groups.

I retrieved the case notes for as many patients as possible who had been registered locally as having died of asthma during 1980-9 (21 case notes out of 40 in total). I assessed six factors which I thought would help determine whether patients had actually had asthma and whether their death had been caused by asthma.

The six factors were history suggestive of asthma (for example, episodic wheezing), objective evidence of reversible airways obstruction (for example, peak expiratory flow charts), age at death (over or under 60 years), smoking history, postmortem evidence of asthma (mucus plugging, overinflated lungs), and the degree of likelihood that death was caused by asthma based on clinical factors or postmortem examination or both.

As this was a retrospective study retrieval of notes was difficult, especially for the earlier years, and information from case notes was patchy. But all the patients studied had asthma written in the first part of the death certificate and had been entered into the local statistics as asthma deaths.

Only six out of 21 case notes contained objective evidence of asthma and 12 contained clear evidence of an alternative cause of death (myocardial infarction (7), epileptic fit·(1), lung cancer (1), lobar pneumonia (1), chronic obstructive airways disease/emphysema (2)). Nineteen of the subjects were aged over 60 and 
14 had smoked cigarettes. Five patients had had a postmortem examination but only one showed evidence of asthma.

\section{Conclusions}

The actual death rate from asthma in West Cumbria seems to be much lower than mortality statistics suggest. Many older patients who probably neither had asthma nor died of asthma may be being entered into the statistics for asthma mortality because of inappropriate use of the word asthma on death certificates, diagnostic transfer, or coding changes.

Concern has been expressed over the accuracy of death certificates in general, ${ }^{5}$ and certification of death from asthma in particular, ${ }^{7}$ but my study suggests that the inaccuracy may be much greater than previously realised. If the experience in other districts is similar to that in West Cumbria, a mortality from asthma of 2000 asthma deaths a year nationally is probably much too high. Perhaps all deaths recorded as due to asthma should be analysed by an independent panel of experts to ensure that the national statistics are correct.

I thank Dr C MacLeod, senior registrar in community health, West Cumbria Health Authority, for help with statistics and information.

1 British Thoracic society. Deaths from asthma in two regions of England. BMJ 1982;285:1251-5.

2 Burney P. Asthma mortality in England Wales; evidence for a further increase, 1974-1984. Lancet 1986;ii:323-6.

3 Rea HH, Scraff R, Jackson R, Beaglehole R, Fenwick J, Sutherland DC. A case controlled study of deaths from asthma. Thorax 1986;41:83-9.

4 Eason J, Markowe HLJ. Controlled investigation of deaths from asthma in hospital in the North East Thames region. BMF 1987;294:1255-8.

5 Burney PGJ. Asthma deaths in England and Wales 1931-85. Evidence for a true increase in asthma mortality. $\mathcal{F}$ Epidemiol Community Health 1988;42:316. 6 Cochrane AL, Moore F. Death certification from the epidemiological point of view. Lancet 1981;ii:742-3.

7 British Thoracic Association. Accuracy of death certification in bronchial asthma. Thorax 1984;39:505.

(Accepted 12 November 1992)

\title{
Education and training of preregistration house officers: the consultants' viewpoint
}

\author{
David H Wilson
}

\section{Abstract}

Objective-To determine the opinions, attitudes, and requirements of consultants responsible for preregistration house officers in the light of the General Medical Council's Recommendations on General Clinical Training.

Design-A questionnaire was piloted asking 28 questions under the headings professional details, present training arrangements, effectiveness of current training, and perceived help required for implementing the recommendations.

Setting-Two teaching hospitals and nine district general hospitals in the Yorkshire region.

Subjects-33 consultants (19 physicians, 14 surgeons) responded to an hour long interview.

Results-The traditional teaching ward round, with clinical meetings, was the main educational provision for house officers. Under a quarter of respondents provided specific teaching, which rarely exceeded 30 minutes weekly. Many delegated teaching to other junior or non-medical staff. Few consultants assessed the effectiveness of teaching, and feedback to juniors was rudimentary. There was strong support for the apprenticeship system and concern that it should not be downgraded. Appointing educational supervisors and introducing a structured educational programme were approved theoretically. Pressure on consultants to work faster, participate in audit and management, and accept financial responsibility for their clinical work, coupled with the reduction in junior doctors' hours, were considered to militate against educational developments. Many respondents felt frustrated and powerless. They would welcome an increased educational role but considered there must be conceptual, contractual, and financial changes.

Conclusions-Fundamental changes are required by both consultants and management before the preregistration year can have proper educational value. Training in educational methods for consultants and a structured curriculum and formative assessment for trainees require recognition and financial support.

\section{Introduction}

In January 1992 the General Medical Council issued revised recommendations on general clinical training. These state, "The goodwill of consultants and of principals in general practice to be appointed as educational supervisors is essential if house officers' expectations are to be fulfilled. This will be forthcoming only if there is full discussion between the universities and all concerned with the pre-registration year, and a realisation by all of the importance of the year to the young doctor." This paper results from initiating that discussion in the Yorkshire health region.

The concept of a nominated personal educational supervisor for each preregistration house officer is an innovation in the recommendations. Currently in a six month appointment a house officer may be attached to one team of consultants for three months and then change to a second team. There is therefore a danger that no one consultant will take specific responsibility for the house officer throughout the whole six months. The recommendations state, "The educational supervisor should help with both professional and personal development and be aware of the PRHO's individual needs ... provide feedback on their clinical progress ... and should personally undertake, and not delegate their tutorial functions."'

\section{Present survey}

The new recommendations were circulated to all consultants concerned in training preregistration house officers in the region. Through conversation, it was soon realised that although consultants welcomed the concept of the educational supervisor theoretically, they did not all wish to be burdened with this increased responsibility. Consequently, to test this viewpoint three educationalists and two consultants helped prepare a questionnaire asking 28 questions under four headings: professional details of the consultants; their present arrangements for training preregistration house officers; their assessment of the effectiveness of this training; and their view of the help required for 